National Marine

Fisheries Service

NOAA
Fishery Bulletin

ar established in 1881 \%
Spencer F. Baird

First U.S. Commissione

of Fisheries and founder of Fishery Bulletin

\begin{abstract}
Many studies underscore the importance of incorporating the effect of environmental data within a life-history-stage-specific framework for determining the recruitment and survival of small pelagic fish. The recruitment of anchovy (Engraulis encrasicolus) in the Gulf of Cádiz (NE Atlantic) is sensitive to the effect of intense easterlies, stratification of the water column, and discharges from the Guadalquivir River on early life stages. As a proof of concept, we have developed the basis for a new Bayesian model with a dual time step resolution: monthly for juveniles and adults, and weekly for earlier life stages. This dual time step resolution resolves environmental effects on prerecruits while simulating the effect of fishing on recruits. Our estimates for juvenile abundances are validated with field data. The Bayesian framework accounts for the uncertainty, thus providing consistent length-frequency estimates and a plausible environmentally driven stock-recruitment relationship.
\end{abstract}

Manuscript submitted 19 January 2017. Manuscript accepted 2 November 2017.

Fish. Bull. 116:34-49 (2018).

Online publication date: 13 December 2017. doi: 10.7755/FB.116.1.4

The views and opinions expressed or implied in this article are those of the author (or authors) and do not necessarily reflect the position of the National Marine Fisheries Service, NOAA.

\title{
Embedding the effect of environmental conditions on recruitment and survival of the European anchovy (Engraulis encrasico/us): a Bayesian model with dual-time resolution
}

\author{
Margarita M. Rincón (contact author) ${ }^{1}$ \\ Ignacio A. Catalán² \\ Samu Mäntyniemi3 \\ Diego Macías 4 \\ Javier Ruiz ${ }^{1}$ \\ Email address for contact author: margarita.rincon@icman.csic.es \\ ${ }^{1}$ Department of Coastal Ecology and Management \\ Instituto de Ciencias Marinas de Andalucía (ICMAN) \\ Consejo Superior de Investigaciones Científicas (CSIC) \\ Campus Universitario Río San Pedro \\ 11519 Puerto Real, Cádiz, Spain \\ 2 Institut Mediterrani d'Estudis Avançats (IMEDEA) \\ CSIC/Universitat de les Illes Balears (UIB) \\ Carrer de Miquel Marquès 21 \\ 07190 Esporles, Balearic Islands, Spain \\ 3 Fisheries and Environmental Management Group \\ Department of Environmental Sciences \\ University of Helsinki \\ P.O. Box 65 \\ Viikinkaari 1 \\ 00014 Helsinki, Finland \\ ${ }^{4}$ Sustainable Resources Directorate \\ Joint Research Centre \\ European Commission \\ Via Enrico Fermi 2749 \\ 21027 Ispra, Italy
}

The physical and trophic environment affects fish stocks and landings (Lloret et al., 2001; Erzini, 2005), particularly for short-lived small pelagic species (Nakata et al., 2000; Guisande et al., 2004; Basilone et al., 2006; Lindegren et al., 2013). This effect is observed at different time scales (Fréon et al., 2005). Short-term synoptic events that last a few days and affect a relatively large area affect mostly the early life stages of fish. For small pelagic fish, stock dynamics are often more dependent on recruitment failure from mortality at early life stages than on variations in fishing effort (Cingolani et al., 1996; Dimmlich et al., 2004). Variability and instability characterize the dynamics of small pelagic fish (Fréon et al., 2005). Their position in the food web and the prominent role of recruitment in population dynamics partly explain the aforementioned dynamics. The inclusion of environmental drivers in predictive recruitment models for these (and other) species has been advocated in the past and is increasing (Barange ${ }^{1}$;

${ }^{1}$ Barange, M. 2001. Report of the first meeting of the SPACC/IOC study group on "use of environmental indices in the management of pelagic fish populations" 
Durant et al., 2013), but the adoption of these drivers for management is not widespread (Fréon et al., 2005; Fréon et al., 2009).

Intense easterlies, stratification of the water column, and the influence of the Guadalquivir river have been identified as the main environmental factors influencing early life stages of the European anchovy (Engraulis encrasicolus) (Ruiz et al., 2006) in the Gulf of Cádiz. The synoptic time-scales of these environmental forcing variables and the nature of the spawning process, with clear, spatially explicit components, suggest that egg and larval abundances can change drastically within a time scale of days (Catalán et al., 2006). Because many environmental databases are structured on a weekly basis, both the natural scale of the environmentally controlled recruitment process and the availability of data suggest that it is sensible to model these early stages at a weekly resolution.

However, for small pelagic fish, fishing-induced mortality may become a dominant element of population dynamics after recruitment (Pinsky et al., 2011; Lindegren et al., 2013). Fisheries data are frequently structured as monthly statistics in publicly available databases. Moreover, the availability of landing data or catch per unit of effort (CPUE) data and the decreased sensitivity of individual fish to short-term synoptic events suggest that it is sensible to model postrecruit processes with a time resolution longer than a week. The change of time scale for the natural processes governing the dynamics of clupeoids during ontogenetic development poses significant challenges for modeling purposes. Restricting the whole model to a resolution that is suitable only for postrecruits (e.g., monthly) would result in a model that misses the impact of oceanographic synoptic events on recruitment. These synoptic events have a time scale of the order of days but their potential impact can be devastating on the survival of eggs and larvae. Ruiz et al. (2009) parameterized the impact of synoptic events through the implementation of monthly averages. However, these averages may hide the real impact of synoptic events. For instance, in spring or summer, a period of several days of calm and sunny weather in the Gulf of Cádiz will result in a warming of the sea surface, thereby triggering spawning of species like anchovy. If this event is followed by days of intense easterlies, spawning will be lost by the advection of eggs by oceanic currents (Ruiz et al., 2006). The time-scale of these synoptic events (several days) cannot be resolved by the monthly averages implemented in Ruiz et al. (2009). A trivial option would be to select the maximum resolution (e.g., weekly) for the whole life cycle. However, this option may render the model numerically intractable owing to the large number of time steps involved. A dual resolution model, with shorter time steps for earlier stages, offers a compromise between the need to resolve the synoptic

(3-5 September 2001, Cape Town, South Africa). GLOBEC Spec. Contrib. 5, 122 p. [Available from website.] scale that forces both eggs and larvae and the need to keep the numerical burden tractable.

A dual resolution model should be able to encompass the change in time scales inherent with ontogenic development. However, the suitability of such a model does not imply the ability to resolve the intrinsic uncertainty that characterizes ecosystem dynamics. This uncertainty demands a probabilistic rather than a deterministic approach (Ruiz and Kuikka, 2012). In fishery research, state-space models, a kind of probabilistic model that describes the probabilistic dependence between the latent state variables and the observed measurements, coupled with Bayesian Markov Chain Monte Carlo (MCMC) methods, provide estimates of abundance while measuring the uncertainty pervasive throughout the life-cycle of individuals. State-space models separate the problem into two stochastic models (Meyer and Millar, 1999; Rivot et al., 2004). The first one, the process model, accounts for the unobservable stochastic variations that govern internal population dynamics. The second one, the observation model describes how the population state is observed and with what uncertainty. The linking of these two stochastic models provides consistent simulation of stock dynamics and computes uncertainty as a natural output (Punt and Hilborn, 1997; Millar and Meyer, 2000).

We describe the implementation of a state-space, size-structured population dynamics model for anchovy in the Gulf of Cádiz. For this model, it is assumed that the environment affects early stages of the life cycle at different time scales, and a von Bertalanffy growth process provides consistent recruitment and length-frequency estimates. The first section of this article is devoted to the description of the conceptual framework necessary to accommodate a dual resolution and environmentally forced formulation into the general population dynamics model (GPDM) described in Mäntyniemi et al. (2015). The second section describes the model outputs, and the third section presents a discussion regarding the validation of our hypothesis and the effectiveness of the proposed tool.

\section{Materials and methods}

For this study, we implemented a Bayesian state-space size-structured population dynamics model. This statespace model included 2 stochastic models, a process model and an observation model. The process model has two modules in order to integrate both environmentally forced recruitment and size-structured stock dynamics. The first one is applied in this study to the environmental conditions in the Gulf of Cádiz but could be extended to model the dynamics of other small pelagic fish species whose recruitment is mainly forced by the environment during their earliest life stages. The second module describes mainly growth and mortality processes. The observation model requires data on catch in numbers, CPUE, and acoustic surveys. The notation for data and model parameters is summarized in 


\section{Table 1}

List of symbols used in the specification of the Bayesian state-space model, a kind of probabilistic model that describes the probabilistic dependence between latent state variables and the observed measurements, used to incorporate an environmentally forced recruitment for European anchovy (Engraulis encrasicolus) in the Gulf of Cádiz, Spain. TL=total length.

\begin{tabular}{|c|c|}
\hline Symbol & Description \\
\hline \multicolumn{2}{|l|}{ Indexes } \\
\hline$k$ and $l$ & Size class, $k, l=1, \ldots, 6$ \\
\hline$t$ & Month, $t=1, \ldots, 222$ \\
\hline$j$ & Week, $j=1, \ldots, 4$ \\
\hline$i$ & Age (months), specified only for individuals between 3 and 5 months old \\
\hline \multicolumn{2}{|r|}{ - } \\
\hline$T_{\mathrm{t}}^{\mathrm{j}}$ & Sea-surface temperature during week $j$ in month $t\left({ }^{\circ} \mathrm{C}\right)$ \\
\hline$W_{\mathrm{t}}^{\mathrm{j}}$ & Number of days that strong easterlies have blown during week $j$ in month $t$ \\
\hline$D_{\mathrm{t}}^{\mathrm{t}}$ & Discharges from Alcalá del Río dam at month $t\left(\mathrm{hm}^{3}\right)$ \\
\hline$C P U E_{\mathrm{t}}$ & Catch per unit of effort at month $t$ (tons/fishing trip) \\
\hline$A_{\mathrm{t}}$ & Stock abundance from acoustic surveys in month $t$ (numbers) \\
\hline$C_{\mathrm{t}}$ & Catch in numbers at month $t$ \\
\hline \multicolumn{2}{|l|}{ Parameters } \\
\hline$\lambda$ & Parameter for the effect of easterlies \\
\hline$\rho$ & Parameter for the effect of discharges \\
\hline$C_{\mathrm{R}}$ & Coefficient of variation of recruitment process \\
\hline$Q$ & Monthly catchability ( fish caught per unit of effort) \\
\hline$L_{\infty}$ & Asymptotic length (cm TL) \\
\hline$\sigma_{L_{\infty}}$ & Standard deviation for the size of large individuals (cm TL) \\
\hline$g$ & Monthly somatic growth rate \\
\hline$F$ & Monthly fishing mortality \\
\hline$M$ & Monthly natural mortality \\
\hline$N^{*}$ & Initial population (numbers) \\
\hline$\eta^{* *}$ & Inverse of the number of fish in a school (numbers/s) \\
\hline$\sigma_{\mathrm{A}}$ & Standard deviation for acoustic surveys \\
\hline $\mathbf{l}_{\mathrm{t}}$ & Column vector of size-class frequencies after recruitment at time $t$ \\
\hline \multicolumn{2}{|l|}{ Fixed parameters } \\
\hline $\min \operatorname{Linf}, \max \operatorname{Linf}$ & Bounds for $L_{\infty}$ in cm TL (see Table 2) \\
\hline minsdLinf, maxsdLinf & Bounds for $\sigma_{L_{\infty}}$ in cm TL (see Table 2) \\
\hline ming, $\operatorname{maxg}$ & Bounds for the expected somatic growth rate (see Table 2) \\
\hline$W_{\mathrm{k}}$ & Weight $(g)$ for a fish in size class $k(a=00029, b=3.3438)$ \\
\hline$f e c$ & Number of eggs per gram spawned by a female $f e c=450$ eggs $/ g$ \\
\hline sexr & Proportion of females in the population, sexr $=0.5$ \\
\hline$m a t_{\mathrm{k}}$ & Maturity at length $k$. If fish in size class $k$ is mature ( $>11.2 \mathrm{~cm} \mathrm{TL})$ is equal to 1 , or, 0 otherwise \\
\hline \multicolumn{2}{|r|}{${ }^{3}$} \\
\hline$B_{\mathrm{t}}(i)$ & Number of anchovies between $i$ and $i+1$ months old at time $t$ \\
\hline$N_{\mathrm{t}}$ & Population of individuals more than 5 months old (numbers) in the stock at month $t$ \\
\hline$R_{\mathrm{t}}$ & Recruits at month $t$ (numbers) \\
\hline$d_{\mathrm{t}}$ & Death of fish at month $t$ (numbers) \\
\hline$s_{\mathrm{t}}$ & Proportion of the population that survives to the next month $t+1$ \\
\hline$p_{\mathrm{t}}$ & Survival probability \\
\hline$q_{\mathrm{t}}$ & Proportion of caught fish to dead fish at month $t$ \\
\hline
\end{tabular}

Table 1 and a formal graphical representation is provided in Figure 1 (an informal and illustrative diagram is available from the following website).

\section{Process model}

We present below a weekly resolution model to explain mathematically the dynamics of anchovy eggs and larvae in the Gulf of Cádiz. The model includes the effect of the environment on these early life history stages and it is designed to be embedded in a GPDM that runs with longer time steps.

Environmentally forced recruitment According to the anchovy spawning dynamics described in Motos et al. (1996) and García and Palomera (1996), it is reasonable to consider that the production of anchovy eggs in the Gulf of Cádiz occurs when there is a sea-surface temperature (SST) increase of at least one degree $\left({ }^{\circ} \mathrm{C}\right)$ between consecutive months and the temperature 


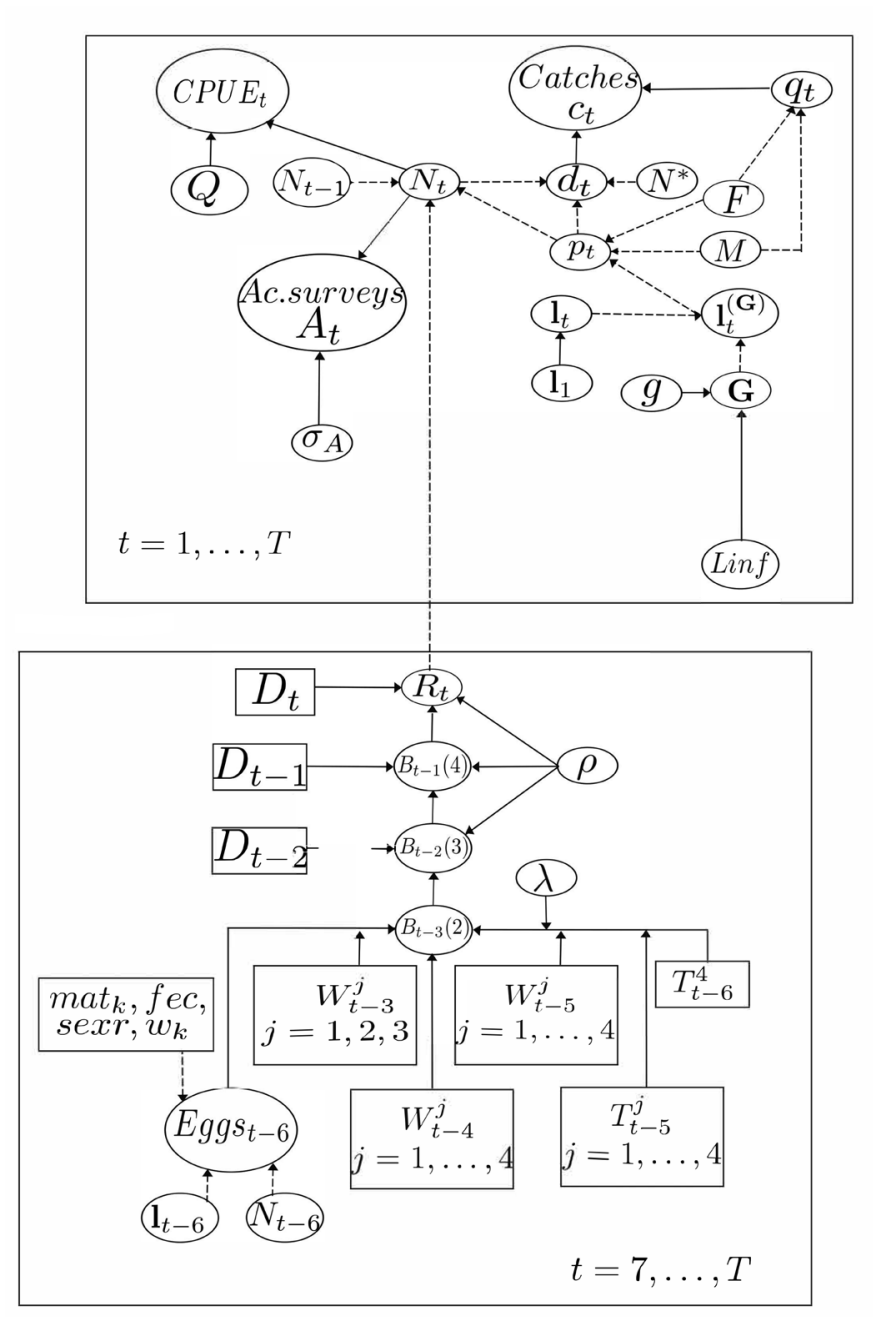

Figure 1

Directed acyclic graph (DAG) of the Bayesian state-space model used to incorporate an environmentally forced recruitment of European anchovy (Engraulis encrasicolus) in the Gulf of Cádiz, Spain. The DAG represents random quantities as elliptical nodes that are connected by arrows indicating conditional dependencies. Rectangular nodes represent known data. The nodes are separated into 2 groups (represented by the large rectangular frames) that determine the life cycle: in the bottom frame are the nodes needed to define processes that take place before recruitment and in the top frame are those used to define processes that take place after recruitment. A description of each node can be found in Table 1.

is above $16^{\circ} \mathrm{C}$ (Ruiz et al., 2006, 2009). To resolve the weekly heat-triggered egg production we assume that it occurs when there is an increment of at least a quarter degree in a week, and therefore consistent with the proposal of a degree per month in Ruiz et al. (2009). Empirical data from other areas suggest that females may spawn on average every three days under suitable temperature conditions (Somarakis et al., 2004). After spawning, strong currents created by easterlies can advect eggs and larvae away from favorable conditions (Catalán et al., 2006). Hence, the number of individuals that survive is negatively influenced by the occurrence of easterlies during the following two months after spawning. After these two months, individuals are better able to control their position in the water and are less vulnerable to currents.

The model resolves the triggering of spawning by SST and egg and larval survival that depend on easterlies through weekly time steps over two months (see Eq.1). Juvenile and adult stages are modeled by using monthly time steps that adequately resolve the dynamics of the population (see Ruiz et al. [2009] for a detailed description of anchovy life stages). Therefore the model resolution changes from weekly to monthly time steps as the development of anchovy individuals moves from egg and larval toward juvenile and recruit stages. This coupling between two different time resolutions is achieved by converting the eggs produced in the first, second, third, and fourth week to juveniles at the 9 th, 10 th, 11 th and 12 th week, respectively. Consequently, $B_{\mathrm{t}}(2)$, defined as the number of individuals that are two months old in month $t$ (first juveniles), is modeled by following a truncated normal distribution and using data from weekly SST at the times of spawning $(9,10,11$ or 12 weeks before) and the weekly effect of easterlies in the preceding 2 months, as follows:

$$
B_{\mathrm{t}}(2) \sim N\left(\overline{B_{\mathrm{t}}(2)}, 200000^{2}\right) \mathbf{I}\left\{B_{\mathrm{t}}(2) \geq 0\right\},
$$

where $\mathbf{I}=$ an indicator variable; and $\overline{B_{\mathrm{t}}(2)}$ is defined as follows:

$$
\overline{B_{\mathrm{t}}(2)}=\operatorname{Eggs}_{\mathrm{t}-3}\left(M_{\mathrm{t}}^{1}+M_{\mathrm{t}}^{2}+M_{\mathrm{t}}^{3}+M_{\mathrm{t}}^{4}\right)
$$

where

$$
\begin{gathered}
M_{\mathrm{t}}^{1}=\left\{\begin{array}{cl}
\mathrm{e}^{-\lambda\left(W_{\mathrm{t}-1}^{4}+\ldots+W_{\mathrm{t}-1}^{1}+W_{\mathrm{t}-2}^{4}+\ldots+W_{\mathrm{t}-2}^{1}\right)} & \text { if } T_{\mathrm{t}-2}^{1}>16, T_{\mathrm{t}-2}^{1}-T_{\mathrm{t}-3}^{4}>0.25, \\
0 & \text { otherwise }
\end{array}\right. \\
M_{\mathrm{t}}^{2}=\left\{\begin{array}{cl}
\mathrm{e}^{-\lambda\left(W_{\mathrm{t}}^{1}+W_{\mathrm{t}-1}^{4}+\ldots+W_{\mathrm{t}-1}^{1}+W_{\mathrm{t}-2}^{4}+\ldots+W_{\mathrm{t}-2}^{2}\right)} & \text { if } T_{\mathrm{t}-2}^{2}>16, T_{\mathrm{t}-2}^{2}-T_{\mathrm{t}-2}^{1}>0.25, \\
0 & \text { otherwise }
\end{array}\right. \\
M_{\mathrm{t}}^{3}=\left\{\begin{array}{cl}
\mathrm{e}^{-\lambda\left(W_{\mathrm{t}}^{2}+W_{\mathrm{t}-1}^{1}+W_{\mathrm{t}-1}^{4}+\ldots+W_{\mathrm{t}-1}^{1}+W_{\mathrm{t}-2}^{4}+W_{\mathrm{t}-2}^{3}\right)} & \text { if } T_{\mathrm{t}-2}^{3}>16, T_{\mathrm{t}-2}^{3}-T_{\mathrm{t}-2}^{1}>0.25, \\
0 & \text { otherwise }
\end{array}\right.
\end{gathered}
$$

and

$$
M_{\mathrm{t}}^{4}=\left\{\mathrm{e}^{-\lambda\left(W_{\mathrm{t}}^{3}+W_{\mathrm{t}}^{2}+W_{\mathrm{t}}^{1}+W_{\mathrm{t}-2}^{4}+\ldots+W_{\mathrm{t}-1}^{1}+W_{\mathrm{t}-2}^{4}\right)} \text { if } T_{\mathrm{t}-2}^{4}>16, T_{\mathrm{t}-2}^{4}-T_{\mathrm{t}-2}^{1}>0.25,\right.
$$

otherwise

where $T_{\mathrm{t}}^{\mathrm{j}}$ and $W_{\mathrm{t}}^{\mathrm{j}}=$ the temperature and the number of days that strong easterlies ( $>30$ $\mathrm{km} / \mathrm{h}$ ) have blown, respectively, during week $j$ in month $t$.

Parameter $\lambda$ accounts for the effect of strong winds and $E g g s_{\text {t-3 }}$ is the number of eggs at time $t-3$ in relation to the population size at the first time step $\left(N^{*}\right)$, whose 
calculation will be explained in the second part of the model. The variance is large enough to avoid any constraint on parameters while the Gibbs sampling algorithm explores the space of possible values for the parameters. Note that corresponds with the assumption of birth in the $j$ th week of month $t-2$.

The regulation of freshwater in the dam of Alcalá del Río has a significant impact on the survival of juveniles at their second (3-4 months old), third (4-5 months old) and fourth (5-6 months old) stages (Ruiz et al., 2009). A lack of discharge, $D_{\mathrm{t}}$, implies low fertilization of the water, and excessive discharges cause individuals to leave the estuary and cause a loss of the protection it provides. The concentration of anchovy as a function of discharges can be described by the standardized normal density function as $\varphi\left(\ln \left(D_{\mathrm{t}}\right)-4.6052\right)$ and by taking the maximum value when $D_{\mathrm{t}}=100 \mathrm{hm}^{3}$ (Ruiz et al., 2009); consequently, the model for second-, third-, and fourth-stage juveniles (3-, 4-, and 5-monthold fish, respectively, at time $t+1, t+2$, and $t+3$, respectively $B_{\mathrm{t}+1}(3), B_{\mathrm{t}+2}(4)$ and $B_{\mathrm{t}+3}(5)$ is formulated as

$$
B_{\mathrm{t}+\mathrm{i}-2}(\mathrm{i}) \sim N\left(\overline{B_{\mathrm{t}+\mathrm{i}-2}(\mathrm{i})}, 2000^{2}\right) \mathbf{I}\left\{0 \leq B_{\mathrm{t}+\mathrm{i}-2}(\mathrm{i}) \leq B_{\mathrm{t}+\mathrm{i}-3}(i-1)\right\}
$$

with

$$
\overline{B_{\mathrm{t}+\mathrm{i}-2}(\mathrm{i})}=B_{\mathrm{t}+\mathrm{i}-3}(i-1) \rho \varphi\left(\ln \left(D_{\mathrm{t}}\right)-4.6052\right) \quad i=3,4,5,(2)
$$

where parameter $\rho$ accounts for the effect of monthly discharges $D_{\mathrm{t}}$. The variance chosen $\left(2000^{2}\right)$ is large enough not to constrain the model while the model searches for appropriate parameter values and keeps the population within sensible limits.

The number of individuals in age group $5\left(B_{t+3}(5)\right)$ could be considered as a function of the number of eggs.

According to Maunder and Deriso (2003), and Mäntyniemi et al. (2013), recruitment process error is accounted with a lognormal process:

$$
\ln \left(R_{\mathrm{t}+3}\right) \sim N\left(\ln \left(\overline{\left.B_{\mathrm{t}+3}(5)\right)}-0.5 \sigma_{\mathrm{R}}^{2}, \sigma_{\mathrm{R}}^{2}\right),\right.
$$

where $\sigma_{\mathrm{R}}^{2}=\ln \left(C_{\mathrm{R}}^{2}+1\right)$, and $C_{\mathrm{R}}$ is a parameter representing the coefficient of variation of $B_{\mathrm{t}+3}(5)$.

Therefore, $R_{\mathrm{t}}$ acts as the link between the environmental forcing of anchovy life stages (Ruiz et al., 2009) and the dynamics of the stock as modeled in Mäntyniemi et al. (2013), where the change in total population size equation is defined as

$$
N_{\mathrm{t}+1}=s_{\mathrm{t}} N_{\mathrm{t}}+R_{\mathrm{t}+1},
$$

where $s_{\mathrm{t}}=$ the proportion of the population that survives to the next time step (see supplementary text for the formal definition of the survival process error);

$N_{\mathrm{t}}=$ the stock population size (individuals with more than 5 months of age) in relation to the population size at the beginning of the first time step, $N^{*}$, i.e., $N_{\mathrm{t}}=1$ and absolute population size is calculated as $N_{\mathrm{t}} N^{*}$; and

$R_{\mathrm{t}+1}=$ the number of recruits at time $t+1$ in relation to $N^{*}$
Size-structured stock dynamics Population of the stock, whose length range is herein defined as $10-22 \mathrm{~cm}$ in total length (TL) according to the ICES reports (see for example ICES $\mathrm{S}^{2,3,4,5,6}$ ), was assumed to be gathered in 6 length intervals of $2 \mathrm{~cm}$ TL each, $J_{\mathrm{k}}=\left[I_{\mathrm{k}}, I_{\mathrm{k}+1}\right), k=1, \ldots$, 6 , where $I_{\mathrm{k}}$ and $I_{\mathrm{k}+1}$ are the size class limits.

Spawning As an approximation for the three days of spawning frequency, and in order to keep computational time reasonable, the female population is assumed to spawn once each week if suitable conditions exist. They are supposed to produce a number of eggs computed with the following dot product:

$$
E g g s_{\mathrm{t}}=\left(\mathbf{l}_{\mathrm{t}} \cdot N_{\mathrm{t}} \mathbf{e}\right),
$$

where $\mathbf{l}_{\mathrm{t}}$ and $\mathbf{e}$ are column vectors with 6 components.

The first column vector denotes the size class frequencies after recruitment, allocating the relative population $N_{\mathrm{t}}$ in the 6 length intervals defined above. The second column vector represents the number of eggs per gram spawned by a mature female in each length class. Each component of column vector $\mathbf{e}$ is calculated as the product of the fixed parameters fec, mat $_{\mathrm{k}}$, sexr, and $w_{\mathrm{k}}$, defined in Table 1 . Note that this number of eggs only becomes effective if spawning conditions settled in Equation 1 are satisfied.

Growth The growth of individuals is assumed to take place instantly at the beginning of each month. The length of individuals at time $t$ (individuals that at time $t-1$ were in length class $k\left(L_{\mathrm{k}}\right)$ ), is assumed normally distributed with an expected value and standard deviation calculated as follows:

and

$$
\mu_{L_{\mathrm{k}}}=L_{\infty}\left(1-e^{-\mathrm{g}}\right)+\frac{I_{\mathrm{k}+1}+I_{\mathrm{k}}}{2} e^{-\mathrm{g}}
$$

$$
\sigma_{L_{\mathrm{k}}}=\sigma_{L_{\infty}} \sqrt{1-e^{-2 \mathrm{~g}}}
$$

\footnotetext{
${ }^{2}$ ICES (International Council for the Exploration of the Sea). 2005. Report of the working group on the assessment of mackerel, horse mackerel, sardine and anchovy (WGMHSA), 6-15 September 2005, Vigo, Spain. ICES CM 2006/ACFM:08, 615 p. [Available from website.]

${ }^{3}$ ICES (International Council for the Exploration of the Sea). 2010. Report of the working group on anchovy and sardine (WGANSA), 24-28 June 2010, Vigo, Spain. ICES CM 2010/ACOM:16, 289 p. [Available from website.]

${ }^{4}$ ICES (International Council for the Exploration of the Sea). 2012. Report of the working group on southern horse mackerel, anchovy and sardine (WGHANSA), 23-28 June 2012, Azores (Horta), Portugal. ICES CM 2012/ACOM:16, 544 p. [Available from website.]

${ }^{5}$ ICES (International Council for the Exploration of the Sea). 2014. Report of the working group on southern horse mackerel, anchovy and sardine (WGHANSA), 20-25 June 2014. Copenhagen, Denmark. ICES CM 2014/ACOM:16, 599 p. [Available from website.]

${ }^{6}$ ICES (International Council for the Exploration of the Sea). 2016. Report of the working group on southern horse mackerel, anchovy and sardine (WGHANSA), 24-29 June 2014, Lorient, France. ICES CM 2016/ACOM:17, 588 p. [Available from website.]
} 
where $L_{\infty}$ and $\sigma_{L_{\infty}}=$ the asymptotic expected value and standard deviation, respectively, for the length distribution and $g$ is somatic growth rate.

The mean value of $L_{\mathrm{k}}$ is an application of the von Bertalanffy growth equation (Quinn and Deriso, 1998) starting from $\frac{I_{\mathrm{k}+1}+I_{\mathrm{k}}}{2}$. Each individual has the possibility to stay in the same length class or move to a larger length class. This transfer is modeled through a transition matrix $\mathbf{G}=\left(g_{\mathrm{k}, 1}\right)_{6 \times 6}$, where $g_{\mathrm{k}, 1}$ denotes the probability that an individual in class $J_{\mathrm{k}}$ grows enough in a month to move to class $J_{l}$.

The size distribution at month $t$ after growth is given by $\mathbf{l}_{\mathrm{t}}^{(\mathbf{G})}=\mathbf{G} \mathbf{l}_{\mathrm{t}}$.

Calculation of $\sigma_{L_{\mathrm{k}}}$ and $g_{\mathrm{k}, \mathrm{l}}$ is described in Appendix 2 of Mäntyniemi et al. (2015).

Mortality and survival A fish in length class $k$ after growth has been completed has three possibilities: to die naturally, be caught, or to survive $\left(\rho_{t, k}, \gamma_{t, k}\right.$, and $p_{t, k}$, respectively), with respective probabilities given by Baranov (Baranov, 1976; Quinn and Deriso, 1998) as follows:

$$
\begin{gathered}
\rho_{\mathrm{t}, \mathrm{k}}=\frac{M}{F+M}\left(1-\mathrm{e}^{-(F+M)}\right) l_{\mathrm{t}, \mathrm{k}}^{(\mathrm{G})}, \\
\gamma_{\mathrm{t}, \mathrm{k}}=\frac{F}{F+M}\left(1-\mathrm{e}^{-(F+M)}\right) l_{\mathrm{t}, \mathrm{k}}^{(\mathrm{G})}, \\
p_{\mathrm{t}, \mathrm{k}}=\mathrm{e}^{-(F+M)} l_{\mathrm{t}, \mathrm{k}}^{(\mathrm{G})},
\end{gathered}
$$

with $F$ and $M$ denoting fishing-induced and natural mortality, respectively (where $M$ and $F$ are assumed as constant in time for all individuals available to the fishery, i.e., bigger than $10 \mathrm{~cm} \mathrm{TL}$ ). Then the proportion of caught fish in length class $k$ from all dead fish is computed as

$$
q_{\mathrm{t}, \mathrm{k}}=\frac{\gamma_{\mathrm{t}, \mathrm{k}}}{1-p_{\mathrm{t}, \mathrm{k}}}
$$

The number of surviving anchovies at time $t$ determined by the probability $p_{\mathrm{t}}=\sum_{\mathrm{k}=1}^{6} p_{\mathrm{t}, \mathrm{k}}$ given in Equation 8 , together with the environmentally forced recruits at time $t+1$ computed in the first part, constitute the population available to fisheries in the stock for time $t+1$ (Eq. 3). The procedure is repeated for each time step.

Length distribution Accordingly, the length distribution in the next time step will be defined as the weighted sum of the known length distribution of recruits (between 10 and $12 \mathrm{~cm} \mathrm{TL)} \mathrm{and} \mathrm{the} \mathrm{length} \mathrm{distribution} \mathrm{of}$ surviving individuals $\left(\mathbf{l}_{\mathrm{t}}^{(\mathrm{S})}\right)$, as follows:

$$
\mathbf{l}_{\mathrm{t}+1}=\left(1-\frac{R_{\mathrm{t}+1}}{N_{\mathrm{t}+1}}\right) \mathbf{l}_{\mathrm{t}}^{(\mathrm{S})}+\frac{R_{\mathrm{t}+1}}{N_{\mathrm{t}+1}} *(1,0,0,0,0,0)^{\mathrm{T}},
$$

where $\mathbf{l}_{\mathrm{t}}^{(\mathrm{S})}=p_{\mathrm{t}} \mathbf{l}_{\mathrm{t}}^{(\mathrm{G})}$.

\section{Observation model}

Catch in numbers Anchovy catches at time $t, c_{\mathrm{t}}$, are assumed to follow a beta-binomial distribution, as follows:

$$
c_{\mathrm{t}} \mid q_{\mathrm{t}}, d_{\mathrm{t}} \sim \operatorname{Betabin}\left(q_{\mathrm{t}} \eta_{\mathrm{t}},\left(1-q_{\mathrm{t}}\right) \eta_{\mathrm{t}}, d_{\mathrm{t}}\right) \quad t=1, \ldots, 222,
$$

where $q_{\mathrm{t}}=\sum_{\mathrm{k}=1}^{6} q_{\mathrm{t}, \mathrm{k}}, d_{\mathrm{t}}=N^{*} N_{\mathrm{t}}\left(1-s_{\mathrm{t}}\right)$ representing all dead individuals (by natural and fishing-induced mortality) at time $t$ and $\eta_{\mathrm{t}}$ as defined in the supplementary text.

This choice corresponds to an overdispersed alternative to a binomial distribution (Gelman et al., 2013). A binomial distribution is too restrictive, considering the schooling and clustering behavior of anchovy (Mäntyniemi and Romakkaniemi, 2002), and a beta-binomial distribution reflects the fact that all individuals do not have the same probability of being captured. Note that the expected value of the distribution $\left(q_{t} d_{t}\right)$ corresponds to Baranov's catch equation.

CPUE The catch per unit of effort at time $t, C P U E_{\mathrm{t}}$ is applied only for the spawning times, i.e when the mean SST of the month is higher than $16^{\circ} \mathrm{C}$ and it has increased at least $1^{\circ} \mathrm{C}$ from the mean temperature of the last month. As extensively discussed in Ruiz et al. (2009), this value is reported yearly but most of the CPUE signal is produced during the spawning period. $C P U E_{\mathrm{t}}$ is normally distributed with a mean proportional to the stock size at time $t\left(N_{\mathrm{t}}\right.$, ) and a very high variance that reflects a vague knowledge about this variable, as follows:

$$
C P U E_{\mathrm{t}} \mid Q, N_{\mathrm{t}} \sim N\left(Q N_{\mathrm{t}}, 10^{5}\right),
$$

where $Q$, = the catchability coefficient.

Acoustic surveys Estimations of the population size by means of acoustic surveys are available for two specific months: June 1993 and June 2004, as in Ruiz et al. (2009). These acoustic data for stock size, $A_{\mathrm{t}}, t$ $=71,215$, provide abundance estimates. They are assumed to follow a normal distribution with unknown variance $\sigma_{\mathrm{A}}^{2}$, that is transformed to a lognormal distribution as follows:

$$
A_{\mathrm{t}} \mid N_{\mathrm{t}}, \sigma_{\mathrm{A}} \sim L N\left(\log \left(\overline{N_{\mathrm{t}}}\right)-0.5 \sigma_{\mathrm{A}}^{2}, \log \left(1+C V^{2}\right)\right) t=71,215,
$$

where $C V=$ the coefficient of variation of $N_{\mathrm{t}}$.

Those acoustic surveys are the only "contact" of the model with nonfishery estimates of stock size. We decided to let variance be a nonfixed parameter to be determined a posteriori by the Gibbs sampler. This decision imposes an additional numerical burden on the exercise, but not an excessive one owing to the low number of estimates, and is justified given the important role of this fishery-independent source of data.

\section{Directed acyclic graph (DAG)}

Figure 1 shows the directed acyclic graph (DAG) for the model. The DAG represents random quantities as elliptical nodes connected by arrows that indicate conditional dependencies. Data are introduced as rectangles and the arrows could be dotted or solid lines that 


\section{Table 2}

Prior probability density functions assigned to the parameters to reflect previous knowledge for the Bayesian state-space model used to incorporate environmentally forced recruitment of European anchovy (Engraulis encrasicolus) in the Gulf of Cádiz, Spain. When the reliability of previous information was considered weak, large variance distributions were selected; such a situation is known as a vague prior, and parameters with a vague prior received a label of "vague" in this table. If there was enough information in the literature, the prior selected is more informative and the literature source is given in this table. The parameter pLinf is such that $L_{\infty}=\operatorname{minLinf}+(\max L i n f-\operatorname{minLinf}) p L i n f$, and analogously $g=\operatorname{ming}+(\operatorname{maxg}-\operatorname{ming}) p g$ and $\sigma_{L_{\infty}}$ $=$ minsdLinf $+(\operatorname{maxs} d \operatorname{Linf}-\operatorname{mins} d \operatorname{Linf}) p s d \operatorname{Linf}$

\begin{tabular}{|c|c|c|}
\hline Parameters & $\begin{array}{l}\text { Prior probability } \\
\text { density function }\end{array}$ & Comments \\
\hline$\lambda$ & $\sim \operatorname{Unif}(0,2)$ & Vague \\
\hline$\rho$ & $\sim N(0.1,0.1)$ & Ruiz et al. (2009) \\
\hline$C_{\mathrm{R}}$ & $\sim \operatorname{Unif}(0,3)$ & Vague, Mäntyniemi et al. (2009) \\
\hline$\eta^{* *}$ & $\sim \operatorname{Beta}(1,1)$ & \\
\hline $1 / \sigma_{\mathrm{A}}^{2}$ & $\sim \operatorname{Gamma}(0.001,0.001)$ & \\
\hline $\ln (F)$ & $\sim N(\ln (0.09), 0.04) \mathbf{1}\{F>0.05\}$ & Giráldez et al. (2009) \\
\hline $\ln (M)$ & $\sim N(\ln (0.035), 0.05) \mathbf{1}\{M<0.08\}$ & Giráldez et al. (2009) \\
\hline$N^{*}$ & $\sim N(\ln (1), 10000)$ & Vague \\
\hline pLinf & $\sim \operatorname{Logitnorm}(0,1)$ & \\
\hline $\max \operatorname{Lin} f=20$ & & Bellido et al. (2000) \\
\hline $\min \operatorname{Linf}=18$ & & Bellido et al. (2000) \\
\hline$p g$ & $\sim \operatorname{Logitnorm}(0,1)$ & \\
\hline $\operatorname{maxg}=0.08$ & & Bellido et al. (2000) \\
\hline ming $=0.05$ & & Bellido et al. (2000) \\
\hline $\begin{array}{l}p s d \operatorname{Linf} \\
\operatorname{maxs} \operatorname{Linf}=3 \\
\operatorname{mins} d \operatorname{Linf}=0.1\end{array}$ & $\sim \operatorname{Logitnorm}(0,1)$ & \\
\hline $\ln (Q)$ & $\sim N(\ln (2000000), 500)$ & \\
\hline $\mathbf{l}_{1}$ & $\sim \operatorname{Dirich}([1 / 1,2 / 2, \ldots, K / K])$ & \\
\hline
\end{tabular}

correspond to logical and stochastic dependencies, respectively. If parameter A follows a distribution dependent on parameter $B$, there is a solid arrow pointing from $B$ to $A$. If parameter $A$ is a function of parameter $\mathrm{B}$, there is a dotted arrow pointing from B to A (Meyer and Millar, 1999). For example, in Figure 1, the relationship of catches $\left(c_{\mathrm{t}}\right)$ with dead individuals $\left(d_{\mathrm{t}}\right)$ and the total probability of being caught $\left(q_{\mathrm{t}}\right)$ is detailed in Equation 9.

\section{Priors}

After an extensive literature search on parameter values for this particular species and area, the data were filtered, preprocessed, and interpreted in terms of reliability by those with an expert knowledge. This method implied an initial inspection of the data distribution and the metadata. If, for example, the age structure from one particular data set was markedly different with respect to that from the Gulf of Cádiz, those data were excluded. Secondly, if the final filtered available data were of poor quality (e.g., produced with a dubious method), the probability density functions (PDFs) were built in a conservative way and at a level of reliability that determines the amount of information provided by the prior distributions (Table 2). When the reliability of previous information was considered weak, large variance distributions were selected. In general, the use of the lognormal distribution was considered adequate for informative priors given the underlying variability and the scarcity of such data. The source of information to derive biological and exploitation-related data was anchovy stocks from European waters and expert-knowledge on those stocks. All parameters were restricted to positive values that were consistent with the processes described. For some parameters (e.g., $\rho$ ), the PDF was modeled according to previous research, whereas for others, such as natural and fishing-induced mortality $(F$ and $M)$, no reliable information was available for the area; hence selected information from similar stocks was used.

Identical monthly distributions for $F$ were chosen on the assumption of a mean annual $F$ of 1.1 corresponding to age-1 fish in the close-by Alborán Sea stock (Giráldez et al. ${ }^{7}$ ). The genetic structure of Alborán Sea

\footnotetext{
${ }^{7}$ Giráldez, A., P. Torres, L. F. Quintanilla-Hervás, J. M. Bellido-Millán, F. Alemany, and M. Iglesias. 2009. Anchovy (Engraulis encrasicolus) stock assessment in the GFCM geographical sub-area GSA 01, Northern Alborán Sea, 18 p.
} 
stock is very similar to that of the Gulf of Cádiz stock (Zarraonaindia et al., 2012). Further, age 1 reflects the average age of most close-by stocks (Pertierra and Lleonart, 1996). A large standard deviation was supplied, so that maximum (annual) $F$ values might reach the maximum $F$ values reported in the literature for the aforementioned stocks (approximately $F=2 /$ year). The prior distribution was constrained at the lower end to $0.05 /$ month, which corresponds to approximately $50 \%$ of the selected average $F$ value for age 1 . The PDF for $M$, for which even less data exist, was based on the age-specific $M$ estimates for age-1 anchovy in the near Alborán Sea (Giráldez et al. ${ }^{7}$ ). Those authors estimated $M$ according to the ProdBiom method (Abella et al., 1997) that is based on Caddy (1991). The large variance assigned to $M$ had an upper boundary of 0.08 , which would yield theoretical annual mortality rates close to $M=1 /$ year, which is $15 \%$ higher than the $M$ value for age-0 anchovy reported from 5 years of surveys of an unfished anchovy stock (Gulf of Biscay; ICES $^{3}$ ).

The bounds for growth parameters $L_{\infty}, \sigma_{L_{\infty}}$, and $g$ (logitnorm function) were constructed on the basis of a single work performed in the Gulf of Cádiz (Table 2) during which biological data were collected fortnightly for 4 years on individuals ranging in size from $4 \mathrm{~cm}$ TL to maximum length. $L_{\infty}$, and $g$ extremes were estimated directly from that series, whereas bounds for $\sigma_{L_{\infty}}$ were considered uninformative and embraced the mean of the standard deviation of $L_{\infty}$ also approximated from that series.

The lower bound for $\lambda$ was chosen by considering the negative effect of winds on recruitment (Ruiz et al., 2006), and the upper bound was chosen on the basis of a preliminary analysis, in which extreme windy conditions from a historical series were considered and that would allow a replacement rate of at least one recruit per female. This assumption prevents collapse in the absence of fishing and adverse environmental conditions.

Constant values used in the model were taken from the literature and were based on expert knowledge, namely the consensus of two experts, and with the assumption that if data were not available from the same stock, they should be taken from the closest (genetically and geographically) stock that experiences a similar exploitation pattern. Using data collected during 4 years in the Gulf of Cádiz (Millán, 1999), we extracted constant parameter values including a $1 / 1$ sex ratio (sexr $=0.5$ ), an average length of maturity equal to 11.2 $\mathrm{cm}$ TL (for females) to define maturity at length class $k$ $\left(m_{\mathrm{k}}\right.$ ) (see Table 1), and $a=0029$ and $b=3.3438$ for the power length-weight relationship, $w_{\mathrm{k}}=a\left(\frac{I_{\mathrm{k}+1}+I_{\mathrm{k}}}{2}\right)^{\mathrm{b}}$. The number of eggs spawned per gram $f e c=450$ eggs/g was

Working paper of the GFCM-SAC-SCSA working group on stock assessment of small pelagic species. Centro Oceanográfico de Málaga, Málaga, Spain. [Available from Centro Oceanográfico de Málaga, Instituto Español de Oceanografia, Puerto Pesquero, s/n Apdo. 285 29640, Fuengirola (Málaga), Spain.] approximated from a review on spawning traits of 22 anchovy stocks in European waters (Somarakis et al., 2004).

\section{Data}

The observation model is defined by using quarterly data on catch (in numbers of fish) and yearly CPUE from January 1988 to December 2004 extracted from ICES reports $\left(\operatorname{ICES}^{2,8,9,10}\right)$. CPUE data were transformed to monthly data with the knowledge that most of the anchovy landings occur during the spawning season. Therefore, it was assumed that CPUE is known only for spawning months and is equal to the CPUE in the corresponding year. Acoustic estimates were provided by ICES $\left(\right.$ ICES $^{2}$ ) for June of years 1993 and 2004. Length frequency of the catches for the same years from ICES annual reports $\left(\operatorname{ICES}^{2,8,9,10}\right)$ was used for validation. Monthly catch (in numbers) and monthly length frequency of the catch data resulted from the assumption that the same amount of fish is landed every month of the quarter and that the third quarter has four months. This assumption results in months of 28 days, 13 months per year approximately, and that the 204 months from January 1988 to December 2004 become 222 months in the process model $(T=222)$.

The environmental covariates SST, discharges from the Alcalá del Río dam, and wind were obtained as follows: SST was extracted from the advanced very high resolution radiometer (AVHRR) sensor data. The nighttime AVHRR PATHFINDER SST v5 weekly means with $4-\mathrm{km}^{2}$ pixel resolution were taken from NASA Physical Oceanography Distributed Active Archive Center (available from website). The region of interest was acquired from the global image, and the arithmetic mean was calculated from the SST of all pixels within this region. Discharges were provided by Confederación Hidrográfica del Guadalquivir (data available from website). The data correspond to the monthly accumulated cubic hectometers that are discharged from the dam each month. Wind data represent the weekly accumulated time (in days) that easterlies faster than 30 $\mathrm{km} / \mathrm{h}$ have been recorded at the meteorological station of Cádiz.

\footnotetext{
${ }^{8}$ ICES (International Council for the Exploration of the Sea). 1990. Report of the working group on the assessment of the stocks of sardine, horse mackerel and anchovy, Copenhagen, 20-29 June 1990. ICES CM 1990/Assess:24, 176 p. [Available from ICES, H. C. Andersens Blvd. 44-46, 1553 Copenhagen, Denmark.]

${ }^{9}$ ICES (International Council for the Exploration of the Sea). 1995. Report of the working group on the assessment of mackerel, horse mackerel, sardine and anchovy, ICES Headquarters, 21 June-1 July 1994. ICES CM 1995/ Assess:2, 329 p. [Available from ICES, H. C. Andersens Blvd. 44-46, 1553 Copenhagen, Denmark.]

${ }^{10}$ ICES (International Council for the Exploration of the Sea). 2000. Report of the working group on the assessment of mackerel, horse mackerel, sardine and anchovy, ICES Headquarters, 14-23 September 2000. ICES CM 2001/ACFM:06, 456 p. [Available from website.]
} 


\section{Model implementation and posterior analysis}

The model was run in the Centre of Supercomputing of Galicia (CESGA) by using the Galician virtual supercomputer (SVG) cluster with an Ivy Bridge microarchitecture (Intel Corp., Santa Clara, CA). The software used was R, vers. 3.2.0 (R Core Team, 2015) and JAGS 4.2.0 (Just Another Gibbs Sampler) (Plummer, 2012a). The $\mathrm{R}$ package rjags links the $\mathrm{R}$ code with the MCMC sampler (Plummer, 2012b; see the supplementary text for the JAGS code used in this study). The cluster required 311.28 hours for 170,000 iterations of two chains running in different cores. The first 10,000 iterations were for adaptation without thinning, and then a thinning of 100 iterations was applied. After a burnin period of 80,000 iterations, potential scale-reduction factors (Gelman et al., 2013) and the Heidelberg and Welch convergence diagnostic (Heidelberger and Welch, $1981,1983)$ were calculated for all monitored parameters by using the coda package (Plummer et al., 2006). The potential-scale reduction factor remained below 1.05 for all of them. Heidelberg and Welch tests were passed for both chains and all parameters.

We used the Kullback-Leibler (KL) divergence (Kullback and Leibler, 1951) as a measure of statistical distance between the obtained distributions. The KL divergence measures the loss of information when the predicted distribution is used instead of the real one. It is also considered as a basis for valid inference in ecological Bayesian approaches (Burnham and Anderson, 2001). It was calculated by using the KLdiv function from the $R$ package flexmix (Grün and Leisch, 2008). In order to compare the estimated time series with available data, the expected value of the quadratic loss and its square root, i.e., mean squared error and root mean-squared error (MSE and RMSE) were calculated. Standardization was necessary to compare yearly model outputs and in situ data for juveniles because they express juvenile abundance at different scales.

\section{Results}

Posterior distributions and the joint posterior of the parameters are displayed in Figure 2 and Supplementary Figure 1, respectively. The posterior for initial population $N^{*}$ is coherent with the initial modeled population in Ruiz et al. (2009), where an uninformative prior was also implemented. The annual fishing-induced mortality mode is higher than the annual natural mortality mode; that finding is consistent with the restrictions placed on the priors, but natural mortality values are very close to the boundary. The mode for parameters $L_{\infty}$, and growth rate $g$ for the von Berttalanfy growth model are close to the middle point of the limits established by the priors according to Bellido et al. (2000). The easterlies parameter $(\lambda)$ is concentrated in values between one and two, and the discharge parameter $(\rho)$ remains in low values with 0.005 as the mode of the distribution.
In Figure 3A, a temporary decay in the modeled recruitment time series from 1992 to 1995 is observed together with a sudden recovery in the next year. Figure 3B shows a consistent evolution of catches compared with the modeled stock population size, a result that is coherent with the assumption of catches proportional to abundance. This proportionality is derived by considering a constant mortality in Baranov's catch equation which is equivalent to the expected value of $c_{\mathrm{t}}$ in Equation 9.

A detailed representation of the juvenile population is presented in Figure 4 to assess the performance of the higher temporal resolution for the first life stages. The dual-time resolution results in a consistent relation between the model output for the juvenile population $\left(B_{\mathrm{t}}(3)+B_{\mathrm{t}}(4), t=1, \ldots, T\right)$ and in situ data (Drake et al., 2007) and offers a smoother version of the former, although the way these data are recorded is prone to sampling noise. There are also some differences between both time series-the most remarkable in year 2000 , which shows a smaller estimated number of juveniles than the number reported from in situ data, as detailed in Table 3.

The model seems to offer a smoother version of the in situ data although the way these data were recorded (Drake et al., 2007) is prone to sampling noise.

An additional contrast between the output and the data not used in the model formulation or parametrization comes from the length structure of the population. The growth module, included through the matrix $\mathbf{G}$, allows the simulation of the length frequency in the stock for each month $\left(\mathbf{l}_{\mathrm{t}}\right)$. The KL divergence between model outputs and ICES data was smaller than 2 in 80.63 of the months considered (Fig. 5), showing that a von Berttalanfy-based matrix could model the length frequency of the population without a significant loss of information in many cases. A lower $\mathrm{KL}$ divergence was obtained in the later years, where the sensitivity to initial values was reduced. Main differences are in the first two length classes, as can be seen in the comparison between modeled and observed length distributions for each month in Supplementary Figure 2. The lengths reported by ICES are in the rank of the estimated length (between the 5th and 95th percentiles) for the first and second length classes in the $62 \%$ and $59 \%$ of all the 222 months, respectively, compared with $63 \%, 63 \%, 81 \%$, and $97 \%$ for the other length classes.

\section{Discussion}

Bayesian models have proven their value for assessing the underlying stock-recruitment relationship of exploited species, along with the associated uncertainty (Dorn, 2002; Mäntyniemi and Romakkaniemi, 2002; Michielsens and McAllister, 2004). In many stocks and particularly in small pelagic fish, the sensitivity of recruitment to the environment impedes the use of traditional stock-recruitment relationships (e.g., Ricker or Beverton-Holt curves) as the unique driver of 


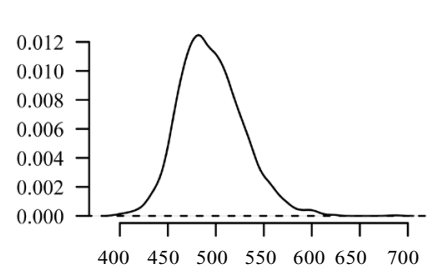

$N^{*}$
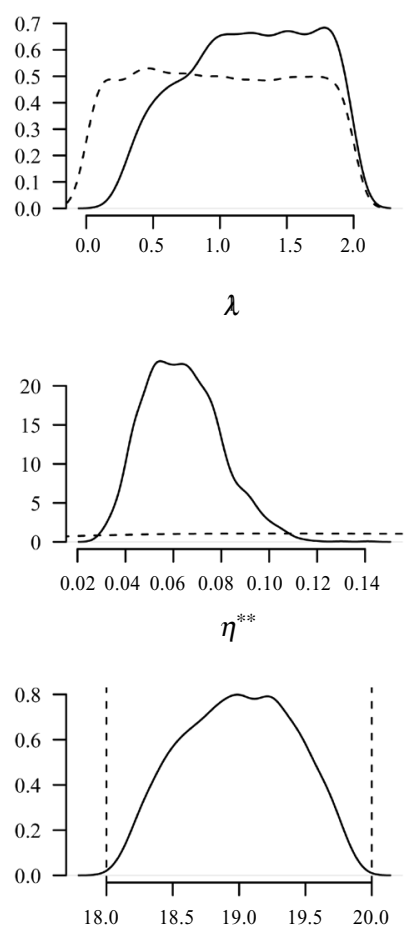

$L_{\infty}$

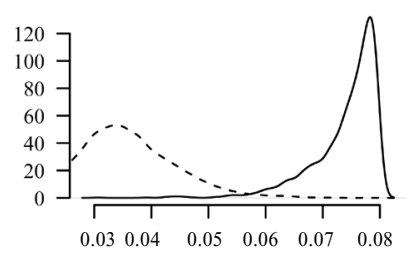

$M$
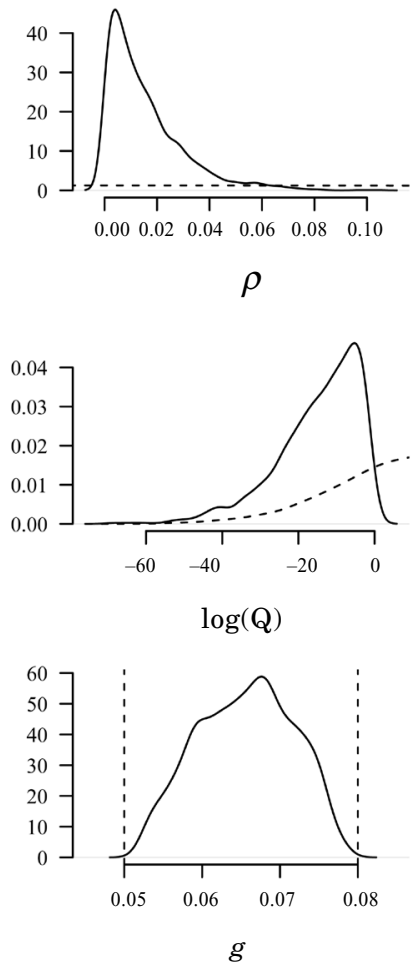
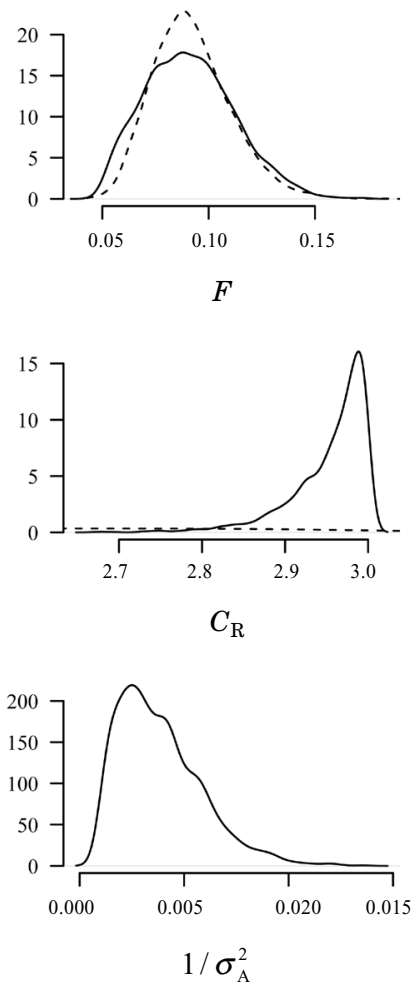

Figure 2

Posterior distributions (solid lines) for the parameters of the model used to incorporate an environmentally forced recruitment of European anchovy (Engraulis encrasicolus) in the Gulf of Cádiz, Spain. Parameters were the following: population size at the first time step $\left(N^{*}\right)$, natural mortality $(M)$, fishing-induced mortality $(F)$, effect of strong winds $(\lambda)$, effect of monthly discharges $(\rho)$, coefficient of variation of recruits $\left(C_{\mathrm{R}}\right)$, inverse of the number of fish in a school $\left(\eta^{* * *}\right)$, Naperian $\operatorname{logarithm}$ of monthly catchability $\log (\mathrm{Q})$, inverse of the variance for acoustic surveys $1 / \sigma_{\mathrm{A}}^{2}$, asymptotic length $\left(L_{\infty}\right)$, and somatic growth rate $(g)$. Dotted lines indicate the prior distributions, except for parameters $L_{\infty}$ and $g$, for which they represent upper and lower bounds.

small pelagic populations (Erzini, 2005; Fréon et al., 2005). However, attempts to include the environment in Bayesian models of recruitment (Ruiz et al., 2009) are hampered by the short time-scale response of early stages to environmental forcing.

The dual-time resolution implemented in this study overcomes this handicap. We were able to integrate within the same model the traditional formulations and parameters of fishery management (e.g., von Bertalanffy growth function, Baranov catch equation, $M$, $F$ ) with advanced tools in oceanographic research (e.g., remote sensing) and to perform this merging in a con- sistent manner with existing data from observations made in the field (e.g., CPUE, landings,or acoustic data).

The proposed dual time resolution does not create a significant numerical burden for the computational effort demanded by a model fully formulated under monthly resolution. The weekly forcing of early stages is implicitly resolved through the $M_{t}^{\mathrm{j}}$ terms (Eq. 1) and the whole MCMC sampling is resolved at monthly time steps. The computational time required by a monthly resolved model is already very high (311 hours in our case with a super-computing center, see also Ruiz et 


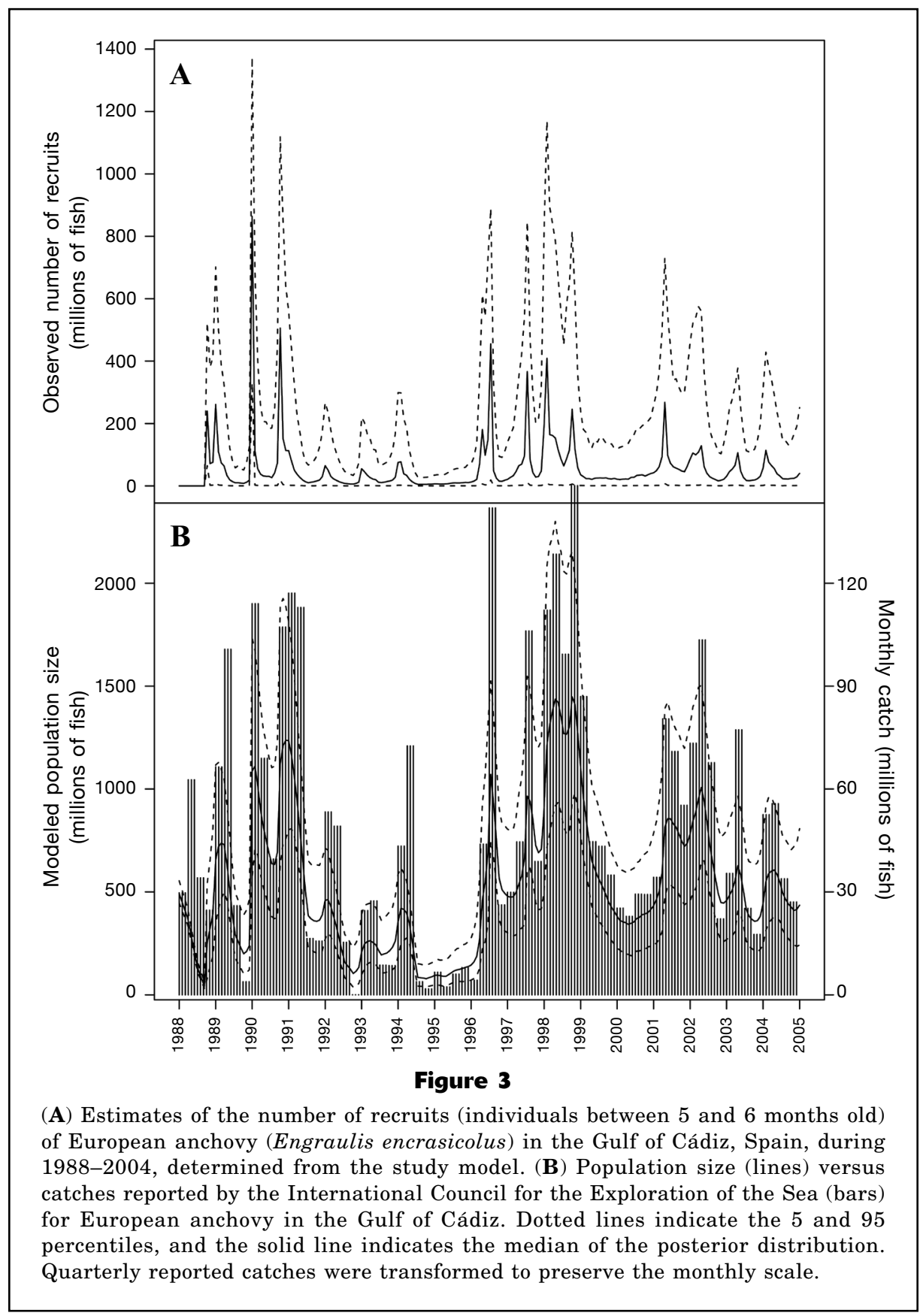

al. (2009). Therefore, the numerical burden necessary to approach convergence would render intractable if we had formulated this model with weekly time steps. Although our computational time demanded by our approach is still large, it is tractable. In particular, with the advances in parallelization and computing power available for research, this tractability can be used with this new approach in the coming years as a tool to run models that resolve fine scales at short operational times.

Admittedly, it would have been more precise to use monthly varying $F$ values, but constant $F$ was chosen for our study to achieve convergence of parameters in reasonable time. In spite of constant $\boldsymbol{F}$, the model resulted in a better coherence between modeled and observed abundances: Figure 4 of this article, in contrast to Figure 7 of Ruiz et al. (2009), illustrates this fact for the seasonal variations and interannual tendencies of juveniles in the Gulf of Cádiz. This improvement is evident if we assess the performance of Ruiz et al. (2009) versus the present model as shown in Tables 3 and 4 . These tables synthesize deviations between model outputs and all available data. These data include those that are incorporated in the modeling exercise (catch, 


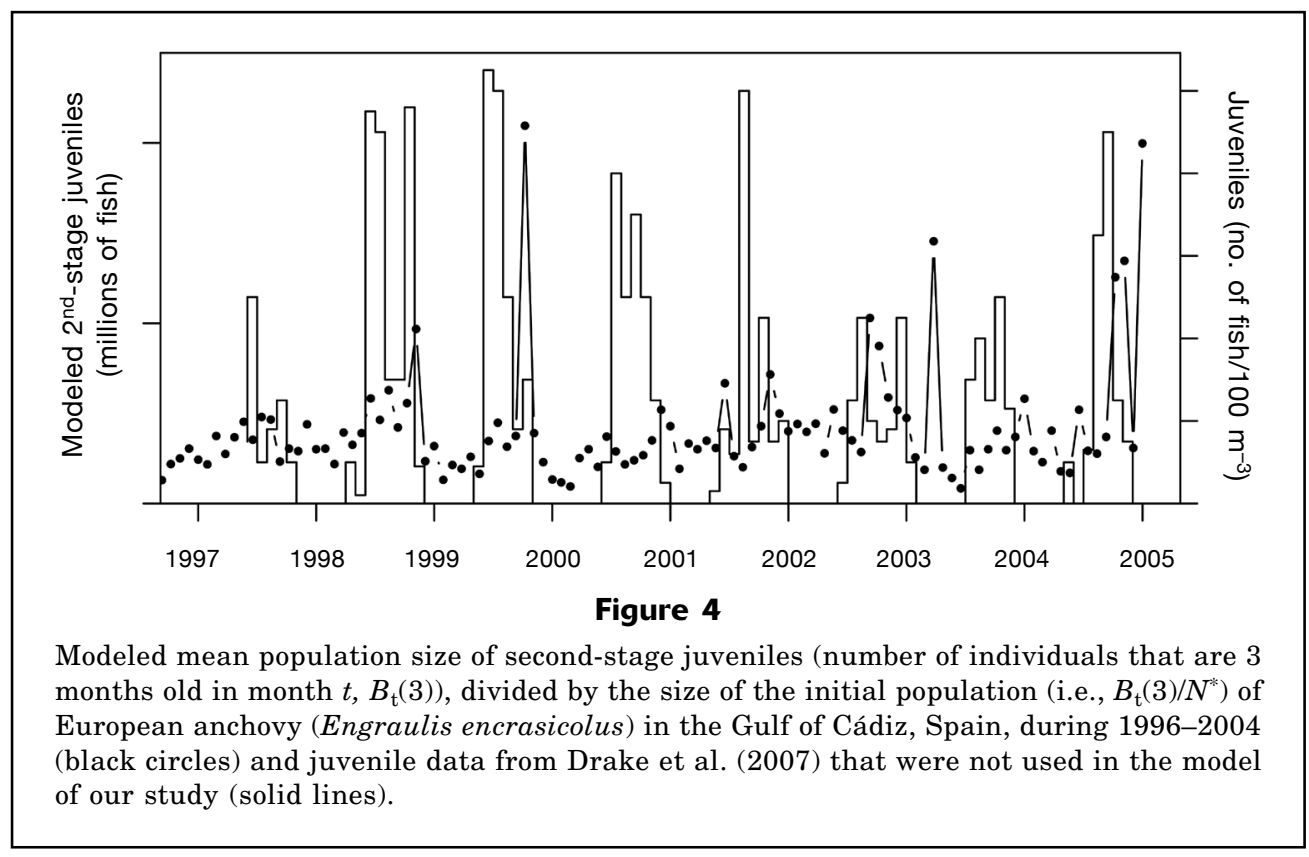

CPUE, and acoustics), as well as those that are not (juveniles and length frequencies). Table 3 shows the capacity of the models to reproduce the yearly evolution of juveniles. The dual-resolution performs better than the monthly model to estimate juvenile abundance in five out of the 8 years and the overall MSE is also better (1.57 vs. 1.83 , respectively). In addition, the difference between CPUE residuals for both models is very small and can be thought of as an improvement of the current model over the former, considering that CPUE is the main source of data of the model in Ruiz et al. (2009) and the high variance defined in Equation 10. This high variance is permissible with some data imperfections such as those identified by ICES, for example, for CPUE in year 1998. These data imperfections are assimilated by this Bayesian exercise with greater flexibility than would have been achieved through deterministic modeling. Another difference between the present model and the Ruiz et al. (2009) model is the intimate connection between landings and $N_{\mathrm{t}}$ defined by Equation 9. This connection decreases the role of CPUE in abundance estimation when compared with the Ruiz et al. (2009) model, a model that does not include reported landings data in the observation model and relies mainly on CPUE.

Another enhancement of the current model is the possibility of calculating catches as a model output which is a preliminary condition for constructing a forecast model for management purposes. Albeit the small RMSE for observed and estimated catches (5 million corresponding to $3.84 \%$ of the maximum value of observed catches) can be a consequence of the process simplification induced by the assumption of constant fishing-induced mortality, it shows the goodness of fit of the model in a plausible "What if" scenario: What

\section{Table 3}

Seasonal performance of 2 models used to incorporate an environmentally forced recruitment of European anchovy (Engraulis encrasicolus) in the Gulf of Cádiz, Spain: the dual-time resolution model of this study and the monthly resolution model of Ruiz et al. (2009). Values are the expected value of the quadratic loss (mean squared error [MSE]) between predicted and observed juvenile abundance for each of the years when the latter available. Predictions and observations were standardized with the mean and variance of the yearly model outputs (for 8 years) before MSE was calculated.

\begin{tabular}{lccc}
\hline Year & $\begin{array}{c}\text { Current } \\
\text { model }\end{array}$ & $\begin{array}{c}\text { Model from } \\
\text { Ruiz et al.(2009) }\end{array}$ & Difference \\
\hline 1997 & 3.3099 & 9.4143 & -6.1044 \\
1998 & 0.0721 & 0.2029 & -0.1309 \\
1999 & 4.0713 & 2.7520 & 1.3193 \\
2000 & 2.7627 & 0.3107 & 2.4520 \\
2001 & 1.2112 & 0.0184 & 1.1928 \\
2002 & 0.9918 & 1.1475 & -0.1557 \\
2003 & 0.2155 & 1.4419 & -1.2264 \\
2004 & 0.0016 & 0.1662 & -0.1646 \\
& & & \\
\hline
\end{tabular}

if catches are proportional to the population, and that scenario is not far from reality according to the results from the previously developed Bayesian model. Although a proportionality between catches and abundance is not necessarily observed and is the subject of hot debate (Pauly et al., 2013), this proportionality is frequently observed in short-lived small pelagic fish (Lloret et al., 2004). 


\section{Table 4}

Interannual performance of 2 models used to incorporate an environmentally forced recruitment of European anchovy (Engraulis encrasicolus) in the Gulf of Cádiz, Spain: the dual-time resolution model of this study and the monthly resolution model of Ruiz et al. (2009). Values are the root mean squared errors between monthly means of estimations from the models and observations from available data (1988-2004). The model of Ruiz et al. (2009) did not estimate catches. Maximum and minimum values for observed catches are 0 and 136 millions of fish, respectively, and maximum and minimum values for observed catch per unit of effort (CPUE) are 0.138 and 1.148 tons/fishing trip, respectively.

\begin{tabular}{lcrr}
\hline & $\begin{array}{c}\text { Current } \\
\text { model }\end{array}$ & $\begin{array}{c}\text { Model from } \\
\text { Ruiz et al. (2009) }\end{array}$ & Difference \\
\hline Catch (millions of fish) & 5.235 & & \\
CPUE (tons/fishing trip) & 0.276 & 0.2734 & 0.0028 \\
Acoustic survey 1993 (millions of fish) & 572.9414 & 185.3100 & 387.6314 \\
Acoustic survey 2004 (millions of of fish) & 107.4575 & 180.7900 & -73.3325 \\
\end{tabular}

The dual resolution also facilitates the embedding of environmental forcing into generalist models, such as the GPDM for fishery management (Mäntyniemi et al., 2015). This integration results in coherence between the model outputs and observed data beyond the initial stages of the life cycle, see for instance Figures 5 and Supplementary Figure 2 that show coherence between the size structures produced by the model and those reported by ICES. The coherence seems to indicate the suitability of the von Bertalanffy model used for Equations 4 and 5, and the bounds settled on for growth parameters provided by Bellido et al. (2000) (see Table 2). Other features observed in the population size-structure also seem to be well reproduced by the model. Therefore, the absence of large sizes and the high concentration of individuals between 10 and $14 \mathrm{~cm}$ TL are consistent with the suggestion that fishing pressure hampers adult survival beyond a year and the population relies on the youngest fish (BOTTOP control, Ruiz et al. (2007)). Nevertheless, discrepancies between model and data frequently occur in the first two length classes (10-12 cm TL and 12-14 cm TL, Suppl. Fig. 2). This result probably reflects the need to ameliorate the transition matrix $\mathbf{G}$ in future versions of the model. In this respect, the inclusion of another length class in the model (e.g., 8-10 cm TL, representing mostly immature fish) seems reasonable according to the recent report of landings data $\left(\operatorname{ICES}^{6}\right)$. Further, the use of a seasonal growth model incorporating temperature effects may improve the observed results.

It is worth underscoring that the model did not previously use any of the in situ data for estimates of early-stage abundance presented in Figure 4 or with the population size structure reported by ICES (and used in the contrast of model versus observation in Figure 5 and Supplementary Figure 2). Therefore, the Bayesian integration of environmental forcing in traditional formulations of fishery management results in outputs that are coherent with field observations. This coher- ence holds over the whole life cycle, even when the observational data have not being previously used in the configuration of the model.

The main feature of the time series, the collapse and recovery between 1994 and 1996, is described in previous works and points to the combined effect of wind and discharges over recruitment (Ruiz et al., $2006,2009)$. The resulting drastic variation in landings is also well resolved by the model. The posteriors of $\lambda$ and $\rho$ in Figure 2 indicate, nevertheless, a higher role of the wind regime in driving the dynamics of the population, consistent with the analysis presented by Rincón et al. (2016). Consistent with a recruitmentdriven fishery, the model transfers these major changes in recruits (Fig. 3A) into large fluctuations of landings (Fig. 3B).

These types of dynamics can be reproduced only by models incorporating the mechanics of environmental forcing on recruitment. Classic models, such as virtual population analysis or extended survivor analysis, may be valid for assessing species with longer life spans. The impact the environment may have on these species results in abundance or size-structure changes that are slow enough to be detected by the models used in yearly evaluations of the stock, even when those models do not incorporate environmental forcings. However, these models are not valid for recruitment-dependent fisheries such as that targeting the European anchovy in the Gulf of Cádiz because stock changes are too fast. Moreover, knowledge of the cause and effect of environment on recruitment (beyond simple statistical correlations) is necessary to reach some degree of predictability in cases where severe and quick changes in recruitment pose heavy challenges for modeling.

The model presented here confirms the critical role of the environment in shaping recruitment and landings of the European anchovy in the Gulf of Cádiz. Compared with previous models, its dual-time resolution improves coherence between model output and field ob- 


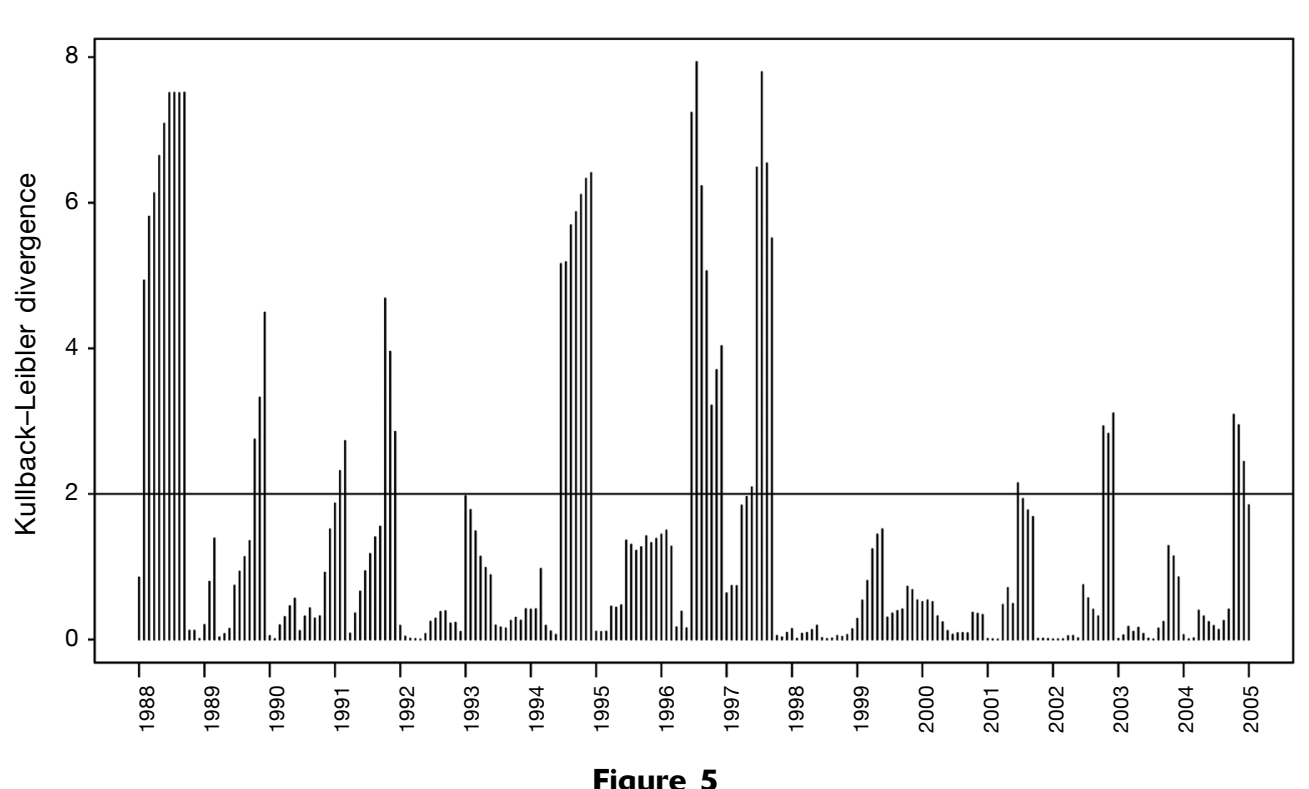

Kullback-Leibler divergence between the modeled and real length-frequency distributions of the population of European anchovy (Engraulis encrasicolus) in the Gulf of Cádiz, Spain, during 1988-2004 grouped into 6 length classes of $2 \mathrm{~cm}$ each from $10 \mathrm{~cm}$ to $22 \mathrm{~cm}$ total length.

servations throughout the life cycle of this fish, including independent observations that represent a genuine validation of the approach (Pauly et al., 2013). Environment clearly influences future recruitment of this species very early in life. For management purposes this fact implies that the concept developed here could be the basis of a tool to estimate recruitment based on data on wind, temperature, and discharge conditions before the fishing season has started. It would then be feasible to define a harvest control rule incorporating this knowledge to reduce risks of a fishery collapse. It must be remarked that in order to have that predictive tool, there is considerable room for improvement in the current model configuration (e.g., varying $F$, etc), but we have proved in this study that even with simpler assumptions, the model can yield useful results.

Finally, although the implementation of our model is designed for the European anchovy in the Gulf of Cádiz, the fact that Equations 1 and 2 can easily be modified for other species and stocks allows the model to be easily adapted and applied to other small pelagic species for which recruitment is key to explain the surplus or collapse of a fishery.

\section{Acknowledgments}

The research leading to these results has received funding from the European Union's Seventh Framework Programme (FP7/ 2007-2013) under grant agreement 244706/ ECOKNOWS project and M. Rincón was funded by P09-RNM-5358 of the Junta de Andalucía.
However, the article does not necessarily reflect European Commission (EC) views and in no way anticipates future policy of the EU in the area. We gratefully thank CESGA (Galician Supercomputing Center) for computational time at the SVG supercomputer and technical assistance.

\section{Literature cited}

Abella, A. J., J. F. Caddy, and F. Serena.

1997. Do natural mortality and availability decline with age? An alternative yield paradigm for juvenile fisheries, illustrated by the hake Merluccius merluccius fishery in the Mediterranean. Aquat. Living Resour. 10:257-269. Article

Baranov, F. I.

1976. Selected works on fishing gear. Vol. 1: Commercial fishing techniques, 631 p. Israel Program for Scientific Translations, Jerusalem.

Basilone, G., C. Guisande, B. Patti, S. Mazzola, A. Cuttitta, A. Bonanno, A. R. Vergara, and I. Maneiro.

2006. Effect of habitat conditions on reproduction of the European anchovy (Engraulis encrasicolus) in the Strait of Sicily. Fish. Oceanogr. 15:271-280. Article

Bellido, J. M., G. J. Pierce, J. L. Romero, and M. Millán.

2000. Use of frequency analysis methods to estimate growth of anchovy (Engraulis encrasicolus L. 1758) in the Gulf of Cádiz (SW Spain). Fish. Res. 48:107-115. Article

Burnham, K.P. and D. R. Anderson.

2001. Kullback-Leibler information as a basis for strong inference in ecological studies. Wildl. Res. 28: 111-119. Article 
Caddy, J.F.

1991. Death rates and time intervals: is there an alternative to the constant natural mortality axiom? Rev. Fish Biol. Fish. 1:109-138. Article

Catalán, I. A., J. P. Rubín, G. Navarro, and L. Prieto. 2006. Larval fish distribution in two different hydrographic situations in the Gulf of Cádiz. Deep-Sea Res., II 53:1377-1390. Article

Cingolani, N., G. Giannetti, and E. Arneri.

1996. Anchovy fisheries in the Adriatic Sea. Sci. Mar. 60 (suppl. 2):269-277.

Dimmlich, W.F.,W. G. Breed, M. Geddes, and T. M. Ward.

2004. Relative importance of gulf and shelf waters for spawning and recruitment of Australian anchovy, Engraulis australis, in South Australia. Fish. Oceanogr. 13:310-323. Article

Dorn, M.W.

2002. Advice on West Coast rockfish harvest rates from Bayesian meta-analysis of stock-recruit relationships. North Am. J. Fish. Manage. 22(1):280-300. Article

Drake, P., A. Borlán, E. González-Ortegón, F. Baldó, C. Vilas, and C. Fernández-Delgado.

2007. Spatio-temporal distribution of early life stages of the European anchovy Engraulis encrasicolus L. within a European temperate estuary with regulated freshwater inflow: effects of environmental variables. J. Fish Biol. 70:1689-1709. Article

Durant, J.M., G. Ottersen, and N. C. Stenseth.

2013. Impact of climate and fisheries on sub-Arctic stocks. Mar. Ecol. Prog. Ser. 480:199-203. Article

Erzini, K.

2005. Trends in NE Atlantic landings (southern Portugal): identifying the relative importance of fisheries and environmental variables. Fish. Oceanogr. 14(3):195-209. Article

Fréon, P., P. Cury,, L. Shannon, and C. Roy.

2005. Sustainable exploitation of small pelagic fish stocks challenged by environmental and ecosystem changes: a review. Bull. Mar. Sci. 76:385-462.

Fréon, P., F. Werner, and F. P. Chavez.

2009. Conjectures on future climate effects on marine ecosystems dominated by small pelagic fish. In Climate change and small pelagic fish (D. M. Checkley Jr., J. Alheit, Y. Oozeki, and C. Roy, eds.), p. 312-343. Cambridge Univ. Press, New York.

García, A. and I. Palomera.

1996. Anchovy early life history and its relation to its surrounding environment in the western Mediterranean basin. Sci. Mar. 60 (suppl. 2):155-166.

Gelman, A., J. B. Carlin, H. S. Stern, D. B. Dunson, A. Vehtari, and D. B. Rubin.

2013. Bayesian data analysis, $3^{\text {rd }}$ ed., 667 p. CRC Press, Boca Raton, FL.

Grün, B. and F. Leisch.

2008. FlexMix version 2: finite mixtures with concomitant variables and varying and constant parameters. J. Stat. Softw. 28(4):1-35. Article

Guisande, C., A. R. Vergara, I. Riveiro, and J. M. Cabanas. 2004. Climate change and abundance of the Atlantic-Iberian sardine (Sardina pilchardus). Fish. Oceanogr. 13:91-101. Article

Heidelberger, P. and P. D. Welch.

1981. A spectral method for confidence interval generation and run length control in simulations. Commun. ACM 24:233-245. Article
1983. Simulation run length control in the presence of an initial transient. Oper. Res. 31:1109-1144. Article

Kullback, S. and R.A.Leibler.

1951. On information and sufficiency. Ann. Math. Stat. 22:79-86. Article

Lindegren, M., D. M. Checkley Jr., T. Rouyer, A. D. MacCall, and N. C. Stenseth.

2013. Climate, fishing, and fluctuations of sardine and anchovy in the California Current. Proc. Natl. Acad. Sci. U.S.A. 100:13672-13677. Article

Lloret, J., Lleonart, J., Solé, I., and J.-M. Fromentin.

2001. Fluctuations of landings and environmental conditions in the north-western Mediterranean Sea. Fish. Oceanogr. 10:33-50. Article

Lloret, J., I. Palomera, J. Salat and J. Sole.

2004. Impact of freshwater input and wind on landings of anchovy (Engraulis encrasicolus) and sardine (Sardina pilchardus) in shelf waters surrounding the Ebre (Ebro) River delta (north-western Mediterranean). Fish. Oceanogr. 13:102-110. Article

Mäntyniemi, S., and A. Romakkaniemi.

2002. Bayesian mark-recapture estimation with an application to a salmonid smolt population. Can. J. Fish. Aquat. Sci. 59:1748-1758. Article

Mäntyniemi, S., S. Kuikka, M. Rahikainen, L. T. Kell and V. Kaitala.

2009. The value of information in fisheries management: North Sea herring as an example. ICES J. Mar. Sci. 66:2278-2283. Article

Mäntyniemi, S., L. Uusitalo, H. Peltonen, P. Haapasaari and S. Kuikka.

2013. Integrated, age-structured, length-based stock assessment model with uncertain process variances, structural uncertainty, and environmental covariates: case of Central Baltic herring. Can. J. Fish. Aquat. Sci. 70:13171326. Article

Mäntyniemi, S. H. P., R. E.Whitlock, T. A. Perälä, P. A. Blomstedt, J. P. Vanhatalo, M. M. Rincón, A. K. Kuparinen, H. P. Pulkkinen and S. Kuikka.

2015. General state-space population dynamics model for Bayesian stock assessment. ICES J. Mar. Sci. 72:22092222. Article

Maunder, M. N. and R. B. Deriso.

2003. Estimation of recruitment in catch-at-age models. Can. J. Fish. Aquat. Sci. 60:1204-1216. Article

Meyer, R. and R. B. Millar.

1999. BUGS in Bayesian stock assessments. Can. J. Fish. Aquat. Sci. 56:1078-1087. Article

Michielsens, C. G. J., and M. K. McAllister.

2004. A Bayesian hierarchical analysis of stock-recruit data: quantifying structural and parameter uncertainties. Can. J. Fish. Aquat. Sci. 61:1032-1047. Article

Millán, M.

1999. Reproductive characteristics and condition status of anchovy Engraulis encrasicolus L. from the Bay of Cadiz (SW Spain). Fish. Res. 41:73-86. Article

Millar, R. B. and R. Meyer.

2000. Bayesian state-space modeling of age-structured data: fitting a model is just the beginning. Can. J. Fish. Aquat. Sci. 57:43-50. Article

Motos, L., A. Uriarte and V. Valencia.

1996. The spawning environment of the Bay of Biscay anchovy (Engraulis encrasicolus L.). Sci. Mar. 60 (suppl. 2):117-140.

Nakata, H., S. Funakoshi and M. Nakamura.

2000. Alternating dominance of postlarval sardine and 
anchovy caught by coastal fishery in relation to the Kuroshio meander in the Enshu-nada Sea. Fish. Oceanogr. 9(3):248-258. Article

Pauly, D., R. Hilborn and T. A. Branch.

2013. Fisheries: Does catch reflect abundance? Nature 494(7437):303-306.

Pertierra, J.P. and J. Lleonart.

1996. NW Mediterranean anchovy fisheries. Sci. Mar. 60 (suppl. 2):257-267.

Pinsky, M.L., O.P. Jensen, D. Ricard and S.R. Palumbi.

2011. Unexpected patterns of fisheries collapse in the world's oceans. Proc. Natl. Acad. Sci. U.S.A. 108: 83178322. Article

Plummer, M.

2012a. JAGS version 3.3.0 user manual, 41 p. Int. Agency Res. Cancer, Lyon, France.

2012b. rjags: Bayesian graphical models using MCMC. R package, vers. 3-9. [Available from website.]

Plummer, M., N. Best, K. Cowles, and K.Vines.

2006. CODA: Convergence diagnosis and output analysis for momc. R News 6(1):7-11. [Available from website.]

Punt, A. E. and R. Hilborn.

1997. Fisheries stock assessment and decision analysis: the Bayesian approach. Rev. Fish Biol. Fish. 7:35-63. Article

Quinn, T .J. and R .B. Deriso.

1998. Quantitative fish dynamics. Oxford Univ. Press, Oxford, UK.

$\mathrm{R}$ Core Team.

2015. R: a language and environment for statistical computing. R Foundation for Statistical Computing, Vienna, Austria. [Available from website, accessed August 2015.]

Rincón, M.M., J.D. Mumford, P. Levontin, A.W. Leach and J. Ruiz.

2016. The economic value of environmental data: a notion- al insurance scheme for the European anchovy. ICES J. Mar. Sci. 73:1033-1041. Article

Rivot, E., E. Prévost, E. Parent and J. L. Baglinière.

2004. A Bayesian state-space modelling framework for fitting a salmon stage-structured population dynamic model to multiple time series of field data. Ecol. Model. 179:463485. Article

Ruiz, J. and S. Kuikka.

2012. Tangled ecosystem models: the temptation of siren songs and silence. Sci. Mar. 76:191-194. Article

Ruiz, J., E. Garcia-Isarch, I. E. Huertas, L. Prieto, A. Juárez,

J. L. Muñoz, A. Sánchez-Lamadrid, S. Rodríguez-Gálvez, J. M. Naranjo and F. Baldó.

2006. Meteorological and oceanographic factors influencing Engraulis encrasicolus early life stages and catches in the Gulf of Cádiz. Deep-Sea Res., II 53:1363-1376. Article

Ruiz, J., R. González-Quirós, L. Prieto, and J. García-Lafuente. 2007. Anchovy in the Gulf of Cádiz: a case of BOTTOP control. GLOBEC International Newsletter 13(2):2224. [Available from Article]

Ruiz, J., R. González-Quirós, L. Prieto and G. Navarro.

2009. A Bayesian model for anchovy (Engraulis encrasicolus): the combined forcing of man and environment. Fish. Oceanogr. 18:62-76. Article

Somarakis, S., I. Palomera, A. Garcia, L. Quintanilla, C. Koutsikopoulos, A. Uriarte and L. Motos.

2004. Daily egg production of anchovy in European waters. ICES J. Mar. Sci. 61:944-958. Article

Zarraonaindia, I., M. Iriondo, A. Albaina, M.A. Pardo, C. Manzano, W.S. Grant, X. Irigoien and A. Estonba.

2012. Multiple SNP markers reveal fine-scale population and deep phylogeographic structure in European anchovy (Engraulis encrasicolus L.). PLoS ONE 7(7):e42201. Article 